\title{
LA ILUMINACIÓN Y EL ALUMBRADO PÚBLICOS
}

\author{
José Antonio Rojas Nicto
}

\section{INTRODUCCIÓN}

T cjos estamos ya de csa hermosa época de mediados de junio de 1825 en la 1 que, los regidores del Cabildo municipal de poblaciones como Aguascalicntes, debatían sobre la conveniencia de que uno de cllos fucra el cncargado de "llevar las cucntas respectivas, así como otros neccsarios que ocurran" $\mathrm{cn} \mathrm{cl}$ ramo del alumbrado público, contando para cllo con "cabos y sercnos a su satisfacción debicndo ayudar de que ćstos cumplan con las obligacioncs", derivadas del cuidado y reparación de los faroles que alumbran las calles; de su atizamiento para que den buena luz hasta las cuatro de la mañana en el verano y hasta las cinco en el invicrno; de su cncendido oportuno para la oración de la noche o cuando se meta la luna; del abasto de accite o manteca y de la sustilución de pabilos para su buen funcionamicnto, así como de la recaudación de ingresos para cubrir los gastos de cada farol a razón de cinco pesos por mes.

El alumbrado público ya no utiliza accite o manteca con pabilos, aunque todavía muchas personas de edad avanzada preparan veladoras con estos materiales. Menos aún los hachones de ocote, aunque en muchas rancherias de nucstro país, esta amable madcra ilumina los rincones de las cocinas campesinas, mientras se "cchan" tortillas en el fogón. Tampoco se ticnen ya las lámparas de trementina que sustituycron a las de accite y manteca, y que daban una luz más limpia, más blanca y' más intensa, allá por los años cuarenta del siglo pasado; ni las lámparas de gas de hidrógeno que sc instalaron por esos mismos años, sustituyendo aquéllas. Hay muchas localidades, incluso, en las que ni siquicra existen ya esas lámparas de luz mercurial que a mediados de los años cuarenta de cste siglo sorprendicron a los moradores de las ciudades por su brillantez. 
EL ALUMBRADO MODERNO

\section{Conceptos básicos}

El alumbrado actual depende de la maravillosa clectricidad. Los sistemas actuales de iluminación en calles y avenidas de poblaciones y metrópolis son eléctricos, con múltiples y diversas condiciones y características físicas, económicas y sociales. Ahora se tienen modernas luminarias, cada vez más distintas en varios órdenes: niveles de luminosidad, volúmenes de electricidad consumida, costos de inversión, de operación y de mantcnimiento, rangos de aceptación social. Sin embargo, aunque actualmente existe una amplia gama de luminarias, éstas se agrupan esencialmonte en tres categorias: incandescentes, fluorescentes y de alta densidad de descarga.

Las lámparas incandescentes emiten luz. porque la electricidad que transita por un mal conductor que ticne un alto punto de fusión - un filamento de tungsteno dentro de un bulbo al vacío o con un gas incrte (argón, halógeno como el flúor o el cloro, nitrógeno, kriptón) para evitar su combustión- hace que éste, justamente por esa deseada incapacidad para conducir electricidad, se caliente de mancra cxtraordinaria (necesariamente más de $500^{\circ} \mathrm{C}$ ) y adquicra un brillo color rojo o rojo blanco. Cuanto más se calicnte el filamento más luz emite. Las luminarias fliorescentes cmitcn una luz por la combustión dcl gas flúor que se encuentra dentro de un bulbo vacio en el que se genera un arco elćctrico ionizado el cual se produce cntre dos polos; gracias a ello cmitc una luz blanca muy parecida a la natural. La posibilidad de gencrar cstc arco eléctrico, esta combustión y, en consecuencia, esta luz, se sustenta en el control de la intensidad de la corrientc, el que sc logra por un importante aditamento llamado balastra, que opera como administrador y regulador, y sin el cual los ricsgos de explosión o de corto circuito scrían máximos. Las luminarias de alta densidad de descarga - las más utilizadas actualmente en árcas abiertas- operan de manera similar a las fluorcscentes; se ionizan vapores y gases a presión cuando, a través de las lámparas, transita una corriente elćctrica cuya intensidad también se controla con una balastra. La mayor o menor presión a la que se encuentran los vapores o gases, determina los dos tipos de lámparas de vapor existentes: de alta o baja presión.

En cl servicio actual de alumbrado de la mayoría de las poblaciones y ciudades de México, sólo se utilizan las luminarias incandescentes, las mixtas (incandescentes con dispositivos para dar luz más blanca), las luminarias de vapor de mercurio y las de vapor de sodio de alta presión.

\section{Características fisicas}

Aparte del discño y la forma, las diferencias físicas entre las luminarias actuales 
se establecen en dos rubros básicos: la elcctricidad que consumen, la luz que emiten y su vida útil. La primera depende de su capacidad o potencia eléctrica, y del tiempo en que sc encuentran encendidas, y se mide multiplicando la potencia de la lámpara por el tiempo de funcionamiento. La potencia eléctrica de la luminaria es la capacidad de la lámpara para que transite por ella la corriente eléctrica llevando, por decirlo así, todos sus efectos, en este caso, la ionización de gases o el calcntamiento del filamento que produce luz. Ésta se identifica también como la carga de la luminaria, y se identifica, precisamente, con un volumen de corriente y con la fuerza de tránsito de dicha corriente. Si la potencia eléctrica se mide en watts y el ticmpo en horas, la energía o electricidad consumida se mide en kilowatts-hora (kwh). Una lámpara cs una carga, como tambićn lo son un motor, un tostador, una licuadora, un refrigerador. En todo estos casos se trata de cargas o dispositivos que toman potencia de una fuente de energía. Por ejemplo, una cafetcra tiene una potencia de 400 watts; una secadora de pclo de 450 watts; una parrilla para calentar alimentos de 600 a 1300 watts; un tostador y una plancha cerca de 1000 watts.

En cuanto a la luz que cada luminaria emite es importante considerar que ésta, cfectivamente, se vincula con detcrminadas características eléctricas. Sin embargo, en lo fundamental depende de la tecnología específica de la lámpara. Así, por ejemplo, una lámpara incandescente con una potencia de 150 watts emite la misma luz que una lámpara fluorescente con potencia de 48 watts aproximadamente, o que una de vapor de sodio de alta presión de sólo 23 a 24 watts de potencia. Estas lámparas se homologan con una potencia diferente en virtud de que, por sus características tecnológicas, emiten la misma luz, la cual se mide en una unidad denominada lúmen.

El lúmen es, entonces, una unidad del flujo luminoso, es decir, de la energía visible cmitida en determinado ángulo por una fuente de luz con la intensidad de una candcla o una bujía, on una unidad de ticmpo; cquivale a la cantidad de luz necesaria para iluminar un pie cuadrado con una intensidad promedio de un piebujía (véasc cuadro 1).

\section{El consumo eléctrico de las lámparas}

El consumo mensual de energía cléctrica de una luminaria se detcrmina multiplicando la potencia de cada tipo de lámpara por el tiempo mensual de encendido; ahora bien, si se considera un periodo de un mes, el tiempo de funcionamiento de las luminarias del alumbrado público se estima en un promedio de 360 horas, 12 horas diarias aproximadamentc, que corresponden al tiempo medio diario requerido de luz artificial, aunque en rigor éste es mayor en el invicrno y menor en el verano, como se pueden notar en cl siguiente cuadro donde se presentan los datos 
CUADRO 1. COMPARACIÓN DE LÁMPARAS EQUIVALENTES

\begin{tabular}{|c|c|c|c|c|}
\hline Caracteristicas & Incandescente & Luz mixta & $\begin{array}{l}\text { Vapor de } \\
\text { mercurio }\end{array}$ & $\begin{array}{l}\text { Vapor de } \\
\text { sodio A.P. }\end{array}$ \\
\hline $\begin{array}{l}\text { Watts por } \\
\text { lámpara }\end{array}$ & 1000 & 500 & 250 & 150 \\
\hline $\begin{array}{l}\text { Lúmen por } \\
\text { lámpara }\end{array}$ & 16500 & 13000 & 13000 & 16000 \\
\hline $\begin{array}{l}\text { Lúmen por watt } \\
\text { Equivalencia }\end{array}$ & 16.5 & 26.0 & 52.0 & 106.7 \\
\hline luminica de unidades & $3 \%$ menos & $20 \%$ más & $20 \%$ más & 1 unidad \\
\hline $\begin{array}{l}\mathrm{kwh} / \mathrm{mes} \\
\text { Horas de ilum. }\end{array}$ & 360000 & 180000 & 112500 & 67500 \\
\hline $\begin{array}{l}\text { por mes } \\
\text { Facturación } \\
\text { mensual } \$\end{array}$ & 263808 & 131904 & 82440 & 49464 \\
\hline
\end{tabular}

Notas: Cálculos aplicando tarifa 5-A aplicada a toda la república, excepto a las ciudades de México, Guadalajara y Monterrey: $\$ / k w h(a g o ` 97)=0.73280$. En México, D.F., Guadalajara y Monterrey aplica la

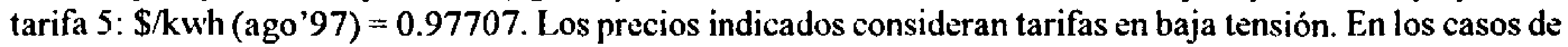
las lámparas de vapor de mercurio y de vapor de sodio en alta presión, se incluyó en los cálculos $25 \%$ de pérdidas por balastro.

FUENTE: Elaborado por la Coordinación de Estudios Municipales del Fideiconiso para el Ahorro de Energia Eléctrica (FIDE) 1997.

para la ciudad de Aguascalientes. ${ }^{1}$ Este tiempo se controla a través de fotoceldas instaladas en cada luminaria, mismas que responden, precisamente, a la iluminación suficientc: la apagan automáticamente en las mañanas cuando la luminosidad suficiente cmpieza a ascender, y la encienden, tambićn automáticamente, cuando esta luminosidad suficiente desciende (véase cuadro 2).

Considerando cste ticmpo promedio de iluminación artificial y la potencia eléctrica de las luminarias, la elcctricidad requerida es de 360000 kilowattshora al mes en el caso de lámparas incandescentes de mil watts; de 180000 kilowatts para las lámparas mixtas de 500 watts; de 112500 para las lámparas de luz mercurial de 250 watts; y, finalmente, de sólo 67500 en el caso de lámparas de vapor de sodio de alta presión con luminarias de 150 watts.

Así, la decisión en torno al tipo de lámparas que ahora debieran instalarse para el servicio de alumbrado pareciera orientarse por las lámparas de menor consumo, hecho que se concretaría siempre y cuando estas lámparas proporcionaran el mismo volumen de luz y, es importante no olvidarlo, su periodo de vida

1 Según los especialistas, 20 a 24 minutos antes y después de la salida del sol se tiene suficiente luminosidad para realizar actividades fuera de las edificaciones, sin necesidad de luz artificial. 
CUADRO 2. TIEMPO DE ILUMINACIÓN ARTIFICIAL (IIORAS)

\begin{tabular}{lrccc}
\hline Aguascalientes & Abril & Junio & Octubre & Noviembre \\
Luminosidad suficicnte & 7.09 & 6.37 & 7.25 & 7.40 \\
Término de iluminación artificial & 7.27 & 6.57 & 7.43 & 7.48 \\
Salida del sol & 7.35 & 7.05 & 7.51 & 8.00 \\
Puesta del sol & 20.07 & 20.36 & 19.15 & 19.30 \\
Inicio de iluminación artificial & 20.15 & 20.44 & 19.23 & 19.38 \\
Ticmpo de iluminación natural & 20.33 & 21.05 & 19.41 & 19.56 \\
Tiempo de iluminación artificial & $11 \mathrm{hs} .7^{\prime \prime}$ & $10 \mathrm{hs} .8 "$ & $12 \mathrm{hs.13}$ " & $12 \mathrm{hs.6"}$ \\
\hline
\end{tabular}

FUENTE: CFD, FIDE, Horario verano en México. Incidencia en el pais, 1997.

útil y sus gastos de mantenimiento no representaran un factor en contra. Analizando los datos técnicos resulta que las lámparas más útiles, eficientes y menos costosas en estos momentos para el alumbrado público son, precisamente, las de vapor de sodio de alta presión, a pesar de que su costo relativo es muy superior al de las otras, como se pucde ver analizando el cuadro que se presentó antes y la tabla comparativa de las lámparas, en cl cuadro 3.

\section{CONSUMO Y GASTO EN ELECTRICIDAD PARA EL AIJUMBRADO PÚBLICO}

\section{Datos tarifarios básicos}

La electricidad que se proporciona para el servicio de alumbrado público se cuantifica en las tarifas de servicio 5 y 5A. Se trata de un servicio que se presta a los 2392 municipios del país y que incluye la encrgía cléctrica utilizada en scmáforos, alumbrado cotidiano y alumbrado ornamental de temporada en calles, plazas, parques y jardines. La tarifa especifica de alumbrado fue creada en el mes de cnero de 1962 , justamentc el de la nacionalización; lucgo de 37 años, sólo los grandes usuarios de las tres zonas metropolitanas del pais - DF, Guadalajara y Monterrey- permanecen en esta tarifa, pucs a principios de los noventa, se abrió la tarifa $5 \mathrm{~A}$ para cl resto de servicios de suministro de alumbrado público, básicamente como un mecanismo de difcrenciación de precios y tarifas orientado a desincentivar el consumo de encrgía en las grandes metrópolis. En 1996 cstas tres ciudades concentraron $27 \%$ de la cnergía cléctrica utilizada para cl servicio de alumbrado público y, por cierto, casi la quinta parte de la que se consume para bombco de aguas potables y negras. Convicne señalar que los servicios de alumbrado se proporcionan en baja o media tensión, es decir con mayor o menor fucrza o voltaje para dar, similarmente, mayor o monor 
CUADRO 3. TABLA COMPARATIVA DE LAS LÁMPARAS MÁS COMÚNMENTE USADAS EN EL ALÚMBRADO PÚBLICO

\begin{tabular}{lccr}
\hline Tipo de lámpara & $\begin{array}{c}\text { Costo relativo } \\
\text { (Promedio) }\end{array}$ & $\begin{array}{c}\text { Eficacia } \\
\text { (lumen/watt) }\end{array}$ & $\begin{array}{c}\text { Vida úfil } \\
\text { (horas) }\end{array}$ \\
Incandescente & 8 & $16-20$ & $1000-2000$ \\
Luz mixta & 27 & $19-26$ & 12000 \\
Fluorescente & 12 & $67-71$ & $9000-12000$ \\
Vapor de mercurio & 76 & $49-58$ & 24000 \\
Vapor de sodio alta presión & 100 & $90-125$ & 24000 \\
Vapor de sodio baja presión & 181 & $150-184$ & 18000 \\
Aditivos metálicos & 97 & $78-90$ & $10000-20000$ \\
\hline
\end{tabular}

FUENTE: Elaborado por la Coordinación de Estudios Municipales del FIDE, 1997.

capacidad de atención a las cargas vinculadas a los equipos o a la magnitud de los scrvicios de alumbrado. ${ }^{2}$

\section{Consumos recientes de electricidad para alumbrado}

En el año de 1996, la clcctricidad consumida por el servicio de alumbrado público apenas represcntó $2.3 \%$ del total de la consumida en el país. En términos absolutos su participación equivale a casi 3000 millones de $\mathrm{kwh}$ (un kwh puede entenderse como la energía cléctrica necesaria para tener encendido un foco de 100 watts durante 10 horas). Por esa encrgía cléctrica, los usuarios -normalmente municipios, pero también fraccionamientos, colonias, poblados y ranchcrías-pagaron 1866 millones de pesos, lo que representa un precio medio de 65.8 centavos por kilowatt-hora, ligeramente superior al precio medio de todos los scrvicios de suministro eléctrico en el país, que fue de 33.22 centavos por kilowatt-hora.

Las tres grandes metrópolis de nuestro país (Distrito Federal, Guadalajara y Montcrrcy) que se agrupan en la tarifa 5 de alumbrado, concentran la cuarta parte de la población y consumen poco más de la cuarta parte de la electricidad utilizada nacionalmente para alumbrado público, aunque por ella aportan prácti-

2 Por las caracteristicas técnicas del suministro, es ligeramente mayor el servicio proporcionado en baja tensión, aunque en este trabajo no se analiza esta diferencia, por lo que los precios que se señalan siempre se refieren a los precios medios, independientemente del nivel de tensión en que se suministra la electricidad para el alumbrado. 
camente la tercera parte del producto monctario que por este servicio se paga en México. A este respecto resulta ilustrativo mencionar que, merced a los programas de sustitución de lámparas, la participación de estas tres metrópolis en el volumen del nuido cléctrico utilizado en cl alumbrado ha ido descendiendo, pucs en 1990 - justamente el año en que se diferenció el servicio para estas tres grandes ciudades-, ćstas concentraban la tercera parte del consumo y aportaban cerca de $40 \%$ de los productos monetarios derivados de este concepto.

A nivel nacional se pucde reconocer una ascenso impresionante del consumo de clectricidad para alumbrado público, aunque un análisis más detallado de su evolución anual nos obligaría a percibir claramente que en 1981 y 1982 hubo un cambio drástico en la misma de dicho consumo. Asimismo nos obligaría a reconocer que a pesar del ascenso de precios - vinculado a la recuperación del costo real del suministro-, el consumo nacional desciende poco, lo que da mucstra de la gran expansión del scrvicio de alumbrado ligado a la expansión urbana.

Un estudio sobrc la cvolución futura de este consumo obligaría a diferenciar el ritmo de crecimicnto de los scricios derivados de la cxpansión urbana, de la atención a zonas que actualmente no cucntan con alumbrado público o de la intensificación del scrvicio en otras que, por razones de seguridad y confort, requieren más iluminación que la actualmente disponible; también de la cvolución del consumo promedio por unidad lumínica, vinculado al cambio técnico que expcrimentan las luminarias. Los factorcs que están atrás de cstos cambios son, sin duda, cl ritmo de crecimicnto de la población, cl cambio en la composición familiar, la mayor o menor capacidad de colonias, poblaciones y municipios para atender este servicio.. Y, finalmente la sustitución de lámparas tradicionalcs por luminarias modernas o el mcjoramiento técnico de éstas.

\section{Una idea sobre los precios}

Analizando un poco las cvolución histórica del precio medio del alumbrado, podemos reconocer que, de 1962 (primer año del que se tienen datos) a 1976, la tarifa de alumbrado descendió en términos rcalcs, de 70 centavos (actuales en 1997) por kwh a cerca de 40 centavos. Una restructuración de precios del sector cléctrico impulsada en plena crisis de 1976, elevó el precio a cerca de 80 centavos; pcro la espiral inflacionaria de esos años deterioró el precio, perdiendo en cinco años ese aumento. Prácticamente desde 1983 se impulsó su recupcración, aunque sólo hasta 1986, sc rcgistraron cambios significativos que llcgaron a 120 centavos por kwh en 1990 y 1991 . Lucgo de estos dos años el precio ha bajado y no ha cxpcrimentado una revisión que modifique esta caida.

No obstante este comportamicnto, el gasto en alumbrado público es muy importante para los municipios, muchos de los cuales no recuperan ese gasto a 


\section{CONSUMO NACIONAL DE ELECTRICIDAD PARA ALUMBRADO PÚBLICO (GWH)}

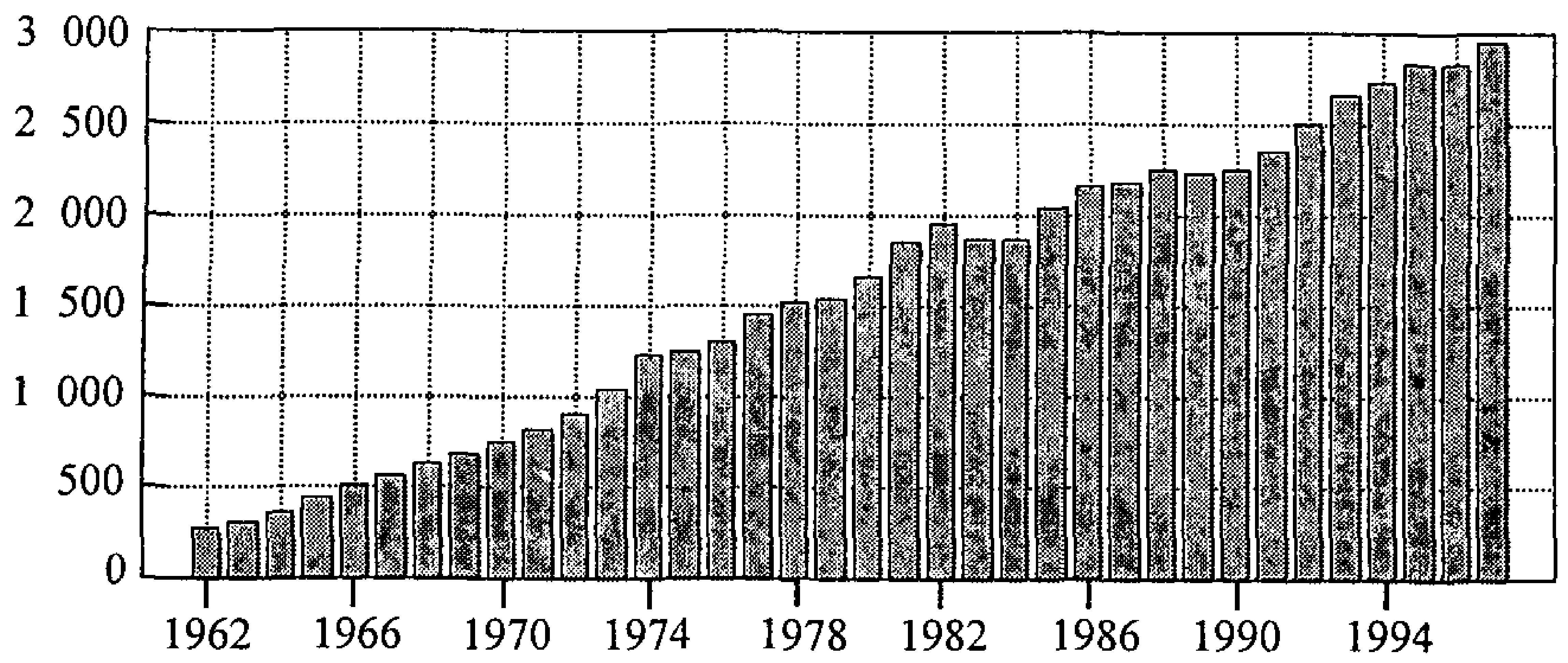

Un gigawatt-hora (gwh) equivale a mil millones de kwh FUENTE: Elaborada con datos de CFE

través de la partida denominada Derecho de Alumbrado Público (DAP) autorizada por los cabildos locales y que, en algunos casos, alcanza hasta $12 \%$ del gasto de cada usuario, sea éste residencial, comercial o industrial, como sucede en Guadalajara.

\section{ALGUNOS EJEMPLOS DE ALUMBRADO PÚBLICO}

\section{Guadalajara (tarifa 5)}

De acuerdo con los datos mediados y fines, la ciudad de Guadalajara tiene una carga de luminarias cercana a los 13000 kilowatts, es decir 13000000 de watts. El $90 \%$ de esta carga corresponde a lámparas de vapor de sodio de alta presión: y $10 \%$ restante a lámparas de mercurio. Los servicios suministrados en media tensión representan $67 \%$ de un total de 354 servicios, entre los que se encuentran calles, manzanas, colonias y grupos de colonias. En 250 de estos 354 servicios el consumo se mide, aunque éstos sólo representan $10 \%$ de las cargas instaladas. El consumo del $90 \%$ restante se calcula con el procedimiento descrito, que asume un encendido de 360 horas al mes. Los derechos de alumbrado que pagan los usuarios se calculan según una cuota fija.

Aguascalientes (tarifa 5 A)

De acuerdo con una estimación reciente, el municipio de Aguascalientes tiene 


\section{PRECIO MEDIO DE LA ELECTRICIDAD PARA ALUMBRADO PÚBLICO EN GUADALAJARA (CTS 97KWH)}

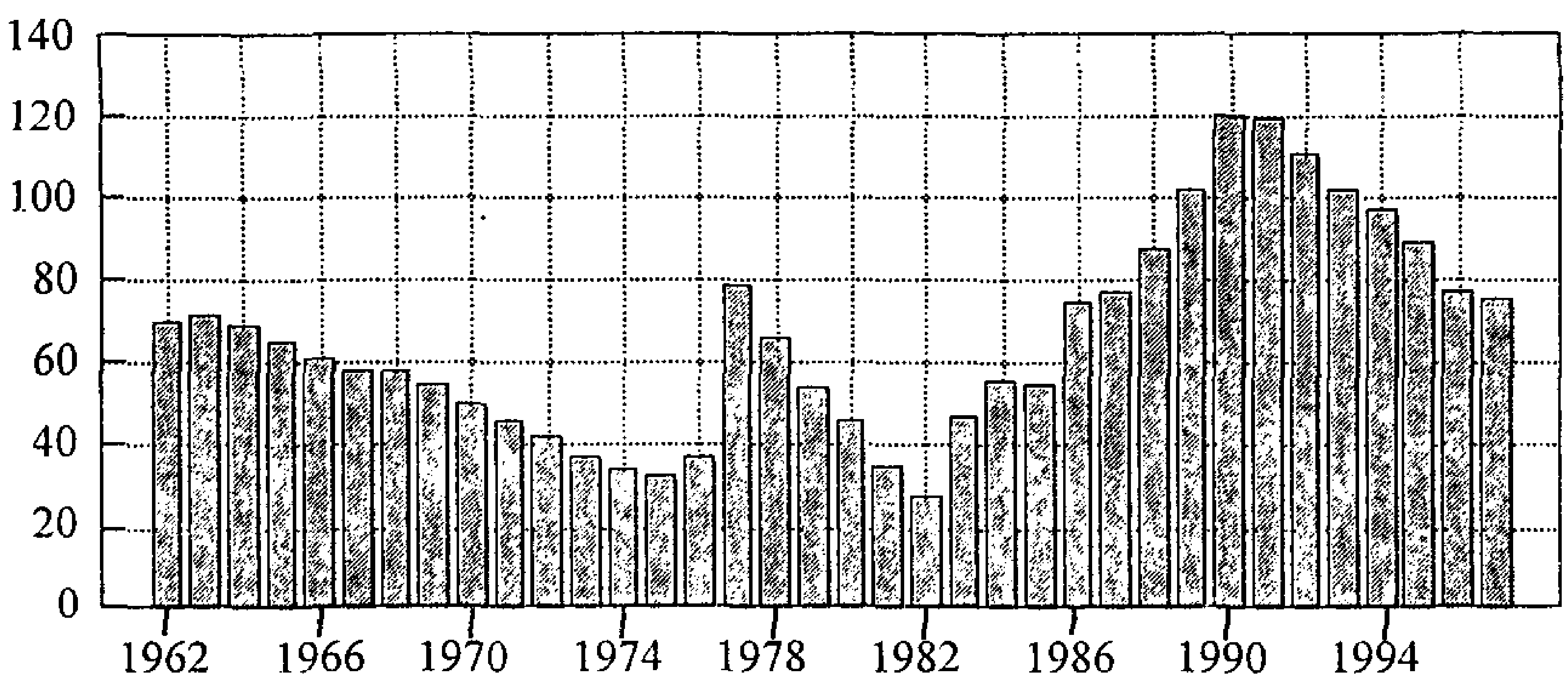

Un gigawatt-hora (gwh) equivale a mil millones de kwh FUENTE: Elaborada con datos de CFE.

28340 luminarias de vapor de sodio de alta presión; 12532 de ellas con potencia de $150 \mathrm{kw}$ y $14281 \mathrm{de} 250 \mathrm{kw}$. En 305 cruceros importantes la potencia de la luminaria es de $400 \mathrm{kw}$ y en nueve de ellos de $500 \mathrm{kw}$. El resto de lámparas del municipio es de luz incandescente con potencias de entre 65 y $100 \mathrm{kw}$ (1213).

En este municipio, el derecho de alumbrado público es de $10 \%$ sobre el pago neto por electricidad de cada usuario. Así, si un usuario residencial paga 80 pesos mensuales por su consumo doméstico, aporta 8 pesos también mensuales al municipio.

El total de luminarias se agrupa en 1252 servicios (considerados como usuarios); de ellos se miden 1182 y se estiman solamente 70 de ellos.

\section{UNA REFLEXIÓN FINAL}

Los avances técnicos logrados en el ámbito del alumbrado y de la iluminación artificial son en verdad sorprendentes. Durante la colonia prácticamente se sustituyeron los hachones de ocote con lámparas de ese aceite de la planta de la familia de las crucíferas que es el nabo; en la época independiente éstas se sustituyeron con luminarias de aceite de trementina, resina semilíquida que se extrae de algunas coníferas; en la época de la reforma aparecieron las lámparas de gas de hidrógeno y las de solarina. En el porfiriato se alumbraron las villas y ciudades con las primeras lámparas incandescentes, compartiendo su función en los años treinta con las lámparas de arco de luz fluorescente y, ya en los sesenta, con luminarias de luz mercurial.

La modernidad trajo las lámparas de vapor de sodio. Y, según los especialis- 
tas, es posible que el nuevo siglo nos sorprenda con lámparas similares, con menor costo inicial, mayor potencia y menor consumo de clectricidad.

Los técnicos han hecho lo suyo. Queda ahora a la sociedad reflexionar sobre los nivcles de iluminación que desca y puede sostener en sus diferentes espacios urbanos; en sus parques, en sus jardines, en sus zonas conflictivas e inscguras; en sus zonas peatonales. La técnica y la racionalidad del alumbrado público están ahí, esperando una evaluación más fina de las socicdades, no sólo en rclación con su gasto; sino con su tipo, nivel c intensidad.

\section{BIBLIOGRAFÍA}

Carranza Castellanos, E., Crónica del alumbrado de México, 4a. ed. México, 1991; CFE y FIDE, Horario de verano en México, Incidencia en el país, México, 1997; CFE, Estadisticas por entidad federativa, diversos años. 
$\int_{a}^{P}$ cr. G/4.

a Comision encargada para formaxiel Plan gue deba sexvin pana el impoxtanite estriblecimicruto del alumbrado de esta Cámdat presenta elsiguiente.

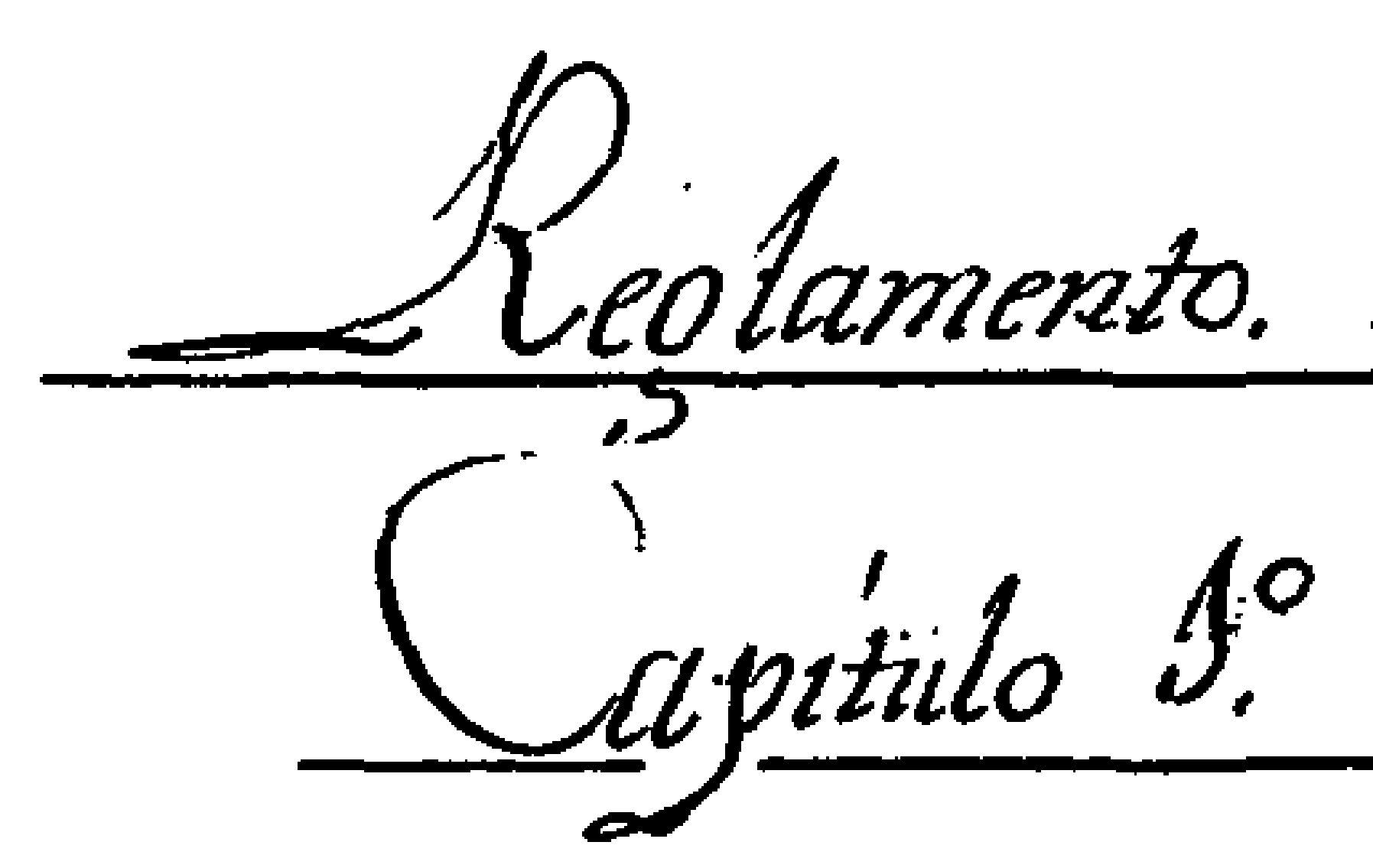

etxt. jo... Sin cmbaxoo de gue paux fudixeciön del alumbeado coin- vendria gue huviere un atdminirtzadur gue entendieza en todo to pextenecicnte a este xamo cun explucion de toda otza atericion; y con tal motibo clebeasele powax un sueldo de txcinta peror mensules a'lomenor; mas como loraxvitzior sean crcaror ycari precaxior, Jurget la co- mirion ineceraxia la esoistcncia y nombxamienzo de dh- cho emplcado, y paxa sustituixlo opina gue debc hacex. Lar fincioner de este, uno de lor Regidoxes de mas dispo. sision paxa el caro, guierr devexá encaxoaxse del citado xa- mo, valiendose puna gee recunde sus trabajor del Cabo ó Cabor gue le mexezcan mas confianza, pagandorele no obstante al dicko Regidox lor mily puecisor gartor de pagel paxa Hebaxistar, Clientär xerpectívair, ari como otxor neceraxior gue ocusxan ().

20... El mirmo Reoidox Atdminírtzadox deveza' sex ioualmente Feroxexo, y como tal se le entxegaxian todor los fondor ario nador à erte xams, qrien lor xecaudaxá pos medio de by

85 
Cabor, sin omitix guemensalmente se vexifigue el cobro de - Jando liguedada toda Clienza de deuda, asipaxa aıbuix lor indirgensabler gastor del ertablecimiento, como para dáx xazor al Ayunzamiento del inoxero y eoxeso de cada lino de los meres.

3:. - Micho Rogidox pondza- Cabor y Sexenor a'suratiffa. cción, deviendo cuydax de gue ertor cumplan con lar Obli- oacióner gue se ler dimaxiar en erte Reglamento.

$$
\begin{aligned}
& \text { Capitulo 2: } \\
& \text { Deloo Cabos }
\end{aligned}
$$

ctut: I: ... Habrá tantor Cabor guantor sean neceraxior a'xarzon the uno pox cada veinte ô. veinte y cinco farder.

2:... Lar Obligaciones de ertor sexan J. cunjdax de gue los $S_{e}$. - xenor cumplar con lo gue se las previene en el Reglamen. -to. 2a. Concurxix con sus xespectibor Sexenor a'xecivix diaxiamente, á la hoxa gue se les señale pox el Regidor el areyte, ô manteca, pavilo, y demar utiler neceraxión paxa el Sexuicio. $3^{\alpha}$ Zelax del areo de los faxoles, yde las comportuzar gue ertor neceríter, dando Cuenta al enun. - ciádo Regidor paxa ru xepaxo. Li. xecaudar los fondos del xamo pox disporirion del Atminirteadox.

3:. Rondaxán todas las noches su pextenencía afin de gue Lor Sexenor no falien en sur puestor, haciendo gue crtor mantengian sur faxoles encendider y con buena luz; de gue no incuzxan lor mirmor en faltar gue les impidan el cumplimienzo de sul Obligacion, y paxa gue el Coviezno gurde 


\section{REGLAMENTO}

La comisión encargada para formar el plan que dcba servir para el importante establecimicnto del alumbrado de esta ciudad presenta el siguientc reglamento.

\section{Capítulo $1^{\circ}$}

Art. $1^{\circ}$. Sin embargo de que para la dirección del alumbrado convendría que hubicse un administrador que entendicra en todo lo pertinente a cste ramo con exclusión de toda otra atención, y con tal motivo dcbérsele pasar un sucldo de 30 pesos mensualcs a lo menos; más como los arbitrios sean escasos y casi precarios, juzga la comisión innecesaria la existencia y nombramiento de dicho empleado, y para sustituirlo opina que debe hacer las funcioncs de éste, uno de los regidores de más disposición para el caso, quien deberá encargarse del citado ramo, valićndose, para que sccunde sus trabajos, del cabo o cabos que le merczcan más confianza, pagándoscle no obstante, a dicho regidor, los muy preciosos gastos de papel para llevar las cuentas respectivas, así como otros necesarios que ocurran.

$2^{\circ}$. El mismo regidor administrador debcrá ser igualmente tesorcro, y como tal se lc entregarán todos los fondos asignados a este ramo, quicn los recaudará por medio de los cabos, sin omitir que mensualmente se verifique el cobro dejando liquidada toda cuenta de deuda, asi para cubrir los indispensables gastos del establecimicnto, como para dar razón al Ayuntamiento del ingreso y egreso de cada uno de los meses.

$3^{\circ}$. Dicho regidor pondrá cabos y screnos a su satisfacción, debicndo cuidar de que ćstos cumplan con las obligaciones que se les demarcan en este reglamento.

Capitulo $2^{\circ}$

De los cabos

Art. $1^{\circ}$. Habrá tantos cabos cuantos scan necesarios a razón de uno por cada veinte o veinticinco faroles.

$2^{\circ}$. Las obligaciones de éstos serán: la. Cuidar de que los señores cumplan con lo que se les previene en el reglamento. 2a. Concurrir con sus respectivos screnos a recibir diariamente, a la hora que se les scñale por el regidor, el aceite o manteca, pabilo, y demás útiles necesarios para cl servicio. 3a. Celar el aseo de 
satisfecho de que los Cabor cumplen con lo gue se les pre-viene en erte aaticulo, devizán a' la hoxa guesexctizen gue rexá alar guatzo de la mañana en el vezano, y alar cinco en el Inviexno, en el Puaxtel pxincipal daix paxte al Oficial de Giradia de las novedader gue hayan ocurxido en la noche, seoun las zecibar de los Serenor, y cl Oficial Las tharmitiza al Gefe Politico.

11:... El Sileldo de lor Cabor sezá a'guince peror mensale os t pudiendoreles aumentax gurndo el estado de lor fondor 20 peimitas.

Ciapitulo 3:

Delos Sezenor.

Hut. 1.. Sas obligacioner de lor Sezenor sezán. 1. Cuidax de lor faxoles gue se les señalaxen, gue sexain de cinco a'seis segun sul dirtancia, de gue no se xompan, y sipox suculpa se gue- bxaxe aloun vidzio, re compondza' de sil cuenta, $20^{\circ}$ gue bor tenoan siempre limpior teniendo cuydado no esten apa. - oador, y atizaxilor paxa gue den buena luz; 30. Lorenen - dexán ala oxacior de la noche, ô cuando semeta la luna, y lor apagaxán cuando esta salga, y en las nocker obruzar harta las guatro de la mañana en el vexano, y alar cinco en el Ynujexno, t.' Se pondxin en las erguinas gue les coxxesponda derde la oxación hasta gue re xetizen, gue sezá. en las hozar señaladas.

20... Fendian su Linterna encendida toda la nocke, ru Lanza, 
los faroles y de las composturas que éstos necesiten, dando cuentas al enunciado regidor para su reparo. 4a. Recaudarán los fondos del ramo para disposición del administrador.

$3^{\circ}$. Rondarán todas las noches su pertenencia a fin de que los serenos no falten en su puesto, haciendo que éstos mantengan sus faroles encendidos y con buena luz; de que no incurran los mismos en faltas que les impidan el cumplimiento de su obligación, y para que el gobierno quede satisfecho de que los cabos cumplen con lo que se les previene en este artículo, deberán, a la hora que se retiren que será a las cuatro de la mañana en el vcrano y a las cinco en el invierno, en el Cuartel principal dar parte al oficial de guardia de las novedades que hayan ocurrido en la noche, según las reciban de los señores, y el oficial las transmitirá al jefe político.

$4^{\circ}$. El sucldo de los cabos será de quince pesos mensuales pudiéndoles aumentar cuando cl estado de los fondos lo permita.

\section{Capítulo $3^{\circ}$}

\section{De los serenos}

Art. $1^{\circ}$. Las obligaciones de los serenos serán: la. Cuidar de los faroles que se les señalen, que serán de cinco a seis según su distancia, de que no se rompan, y si por su culpa se quebrare algún vidrio, se compondrá de su cuenta. 2a. Que los tenga sicmpre limpios teniendo cuidado [de que] no estén apagados, y atizarlos para que den buena luz. 3a. Los encenderán a la oración de la noche, o cuando se meta la luna, y los apagarán cuando ésta salga; y en las noches oscuras hasta las cuatro de la mañana en el verano, y a las cinco en el invierno. $4 \mathrm{a}$. Se pondrán en las esquinas que les corresponda desde la oración hasta que se retiren, que será en las horas señaladas.

$2^{\circ}$. Tendrán su lintcrna encendida toda la noche, su lanza y pito; éste les servirá para hacer scña a los otros serenos cuando los necesiten reunir por alguna novedad que ocurra, y desde las diez de la noche comenzarán a anunciar la hora, con las novedades de la atmósfera, lo que repetirán a cada cuarto de hora.

$3^{\circ}$. Sicmpre que algún vecino los llame para que les traiga al confesor, médico o partera, lo harán de uno a otro screno, conduciéndolos hasta la casa donde los necesitaren, y lo mismo hará a su vuelta.

$4^{\circ}$. Cuidarán del silencio y buen orden de la ciudad, no permitiendo escándalos de gritos, borrachos, ni parados en las esquinas, puertas y zaguanes desde las horas que cmpiczan a funcionar, y si fucren sospechosos, los conducirán al cuartcl principal avisando al cabo cuando se retiren, así como de las demás novedades que ocurran.

$5^{\circ}$. Si encontraren alguno, o algunos con envoltorios o robos, como cuales- 
y Pito; este les sexvizá para hacex seña a'lor otxor Sexe. -nor guando lor neceriter xurnix pox alorma novedad ge o curaxa, y desde las diez de la noche comensaxa' à anun. -ciax la hoxa, con las novedades, de la admorfera, lo gue xepetixán a cada guarto de horox.

3:... Siempue gue aloun vecino lon llame paxa gue les thai. - qa al Conferox, Hedico, it Maxtera, lo haxán de uno a' otxp Sezeno, conduciendolor hasta la Cara donde lonece. -sitazen, y lo mirmo haxa' a'ruvuelta?.

4.... Cirydazán del cilencio, y buren ozden de la Ciudad, no pam. tiendo ercandalor de gizitor, boxzachos, ni paxador en las esguinar, puextas y Saguanes desde lar hoxar gue empie. -san a'funcionax, y sifuezerr sogpechoror, lor conducixán al Cuaxtel pxincigal avisando al Cabo guando rezetizen, asi como de las demar novedader gue ocuxxand.

$S^{\circ}$.. . Siencontzaxen alguno, ô alounor con emboltoxior ô xo. -bor; como gualerguiexa cosa guese haller en la Calles zizada, lo entregaxain en el mirmo Cuaxtel paxa elco-nocimiento de lor Tuecer.

6‥ Ertaxán en todo sugetor a'sus Cabor a'guiener debcxán xeconocex como a'sus Pefer; susucldo sexa' pox a' hoxa de dies peror, deviendoreles suvíx a'doce, huego gue haya for. - dor paxa ello.

C...] 
quiera cosa que se hallen en la calle tirada, lo entregarán en el mismo cuartcl para el conocimiento de los jueces.

$6^{\circ}$. Entran en todo sujctos a sus cabos a quienes deberán reconocer como sus jefes; su sueldo scrá por ahora de dicz pesos, debiéndoseles subir a doce, luego que haya fondos para cllo.

\section{Regulación del costo}

Cada farol, según lo ha acreditado la experiencia, bien que cn época en que está la manteca barata, importa cinco pesos cada mes, por lo que resulta de gasto en los que renta doscientos pesos.

Arbitrios para subvenir a este gasto

Treinta pesos que da el comercio

030.0

Scsenta pesos más o menos que producen las carnes de res, cerdos,

$y$ un real a la carga de harina

060.0

Suma

090.0

Nuevos arbitrios escogidos y propuestos al gobierno para llenar el déficit

Se gradúa de entrada de vino de jèrez al mes

una carga que se pensiona en docenas

001.4

De cacao Guayaquil, dos cargas en el referido mes a un peso $\quad 002.0$

De cacao Tabasco tres cargas a 2 pesos en el mes

006.0

De aguardiente tres barriles a 1 peso en el mes

003.0

Una carga de coquito de aceite a 2 rr. en id.

000.2

Ocho cargas de lana a 2 rr. en id.

002.0

Doce cargas de algodón a $1 r$. en id.

001.4

Diez dichas de jabón a 1r. en id.

001.2

Una carga de chilc a $2 \pi r$. en id.

000.2

Ocho cargas de dulce a $2 \pi r$. en id.

002.0

Dos cargas de azúcar a 4rr. en id.

001.0

Sebo terciado 10 cargas a $1 r$. en id.

001.2

Sal diez cargas a $2 \mathrm{rr}$. en id.

002.4

Arroz cinco cargas a 1 r. en id.

000.5

De plomo y greta cuatro cargas en el mes a $1 r$.

000.4

Mezcal de tequila 9 cargas en id. a $1 p$.

009.0

Papel una carga en id. a $4 p$.

De cera en marqueta una carga en id. a $2 p$. 002.0

De fierro 9 cargas en id. a $1 \mathrm{p}$. 009.0

De acero una carga en id. a 12rr. 001.4 
OBIERNO SUPREMO

DEL ESTADO LIBRE

9

de Zacatecass.

Seccion

di

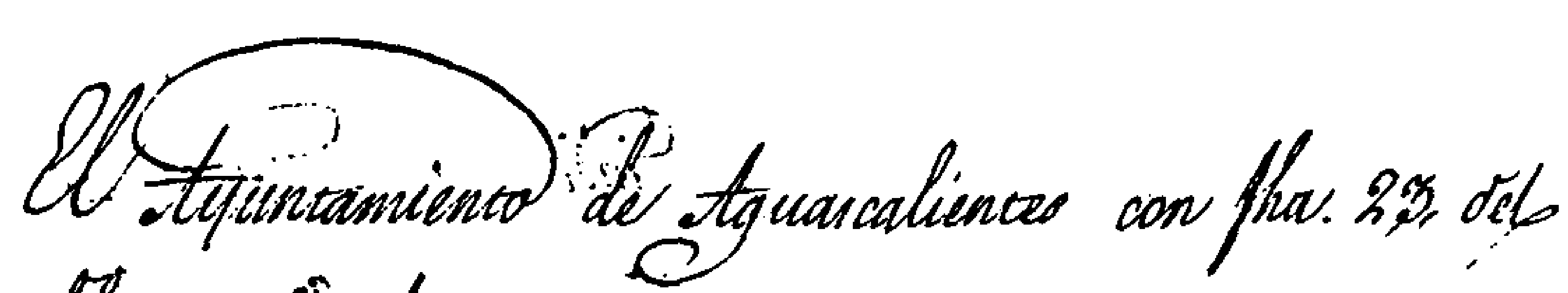
Apo. me dice lo gue sigue!

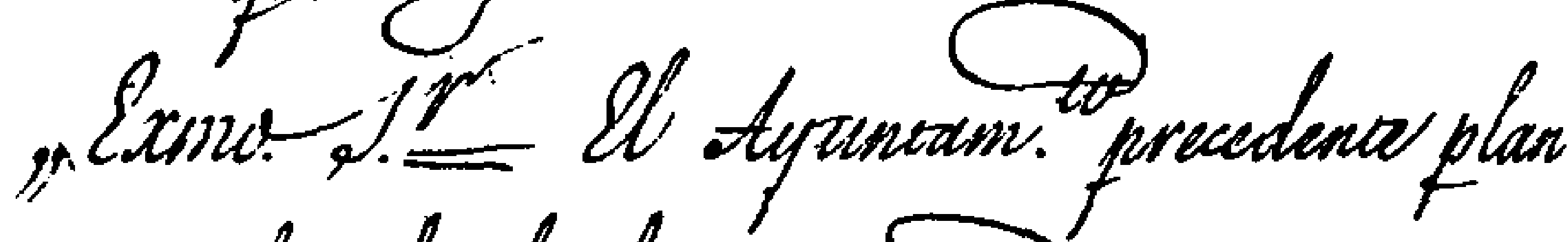
tevo el pivoryecte de alumbrado contoruyento quarenows faroles de gidrio de donacioss que ranios parciculanes hiccieron parr. el efecto, mai caino para la Soscincion peremne del Findicado, of Serrinos que los Gevardacen fus eie indipemable proyectar arbicriot, tocaron en el des tomar treinta por que menialm. da el Comercis pa. pagar twriguardar q. con' el nombre de Serenos

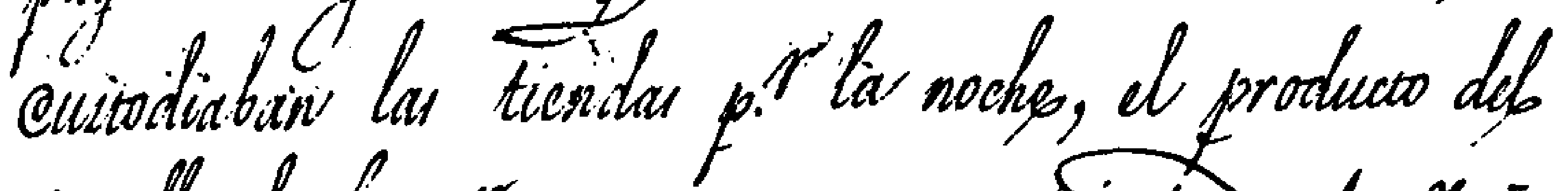

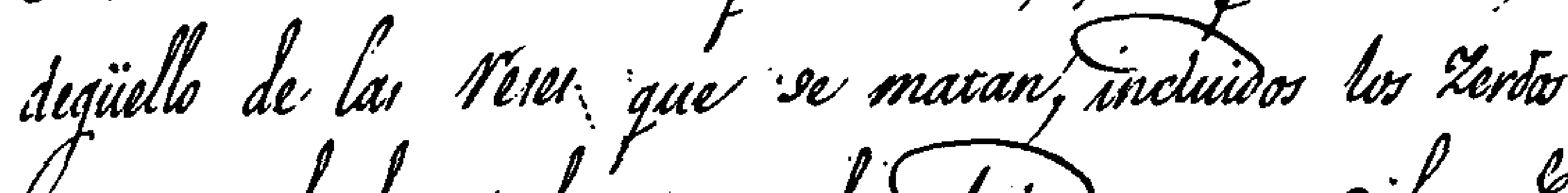
us un mal do cada canga de trina, aup cobro g.

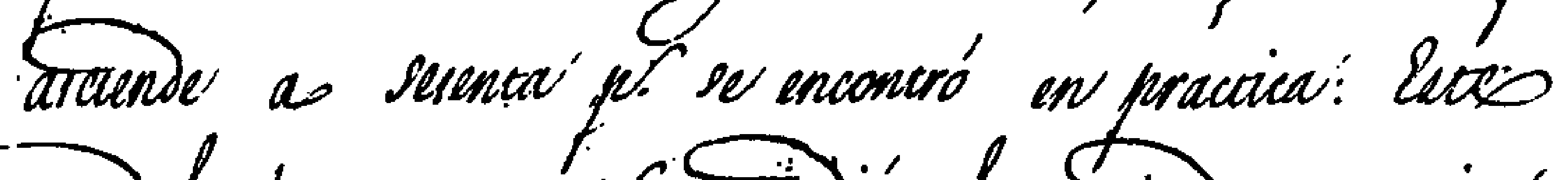
$C$ cawal de mosenta pe prectandió el preciado ancoriors

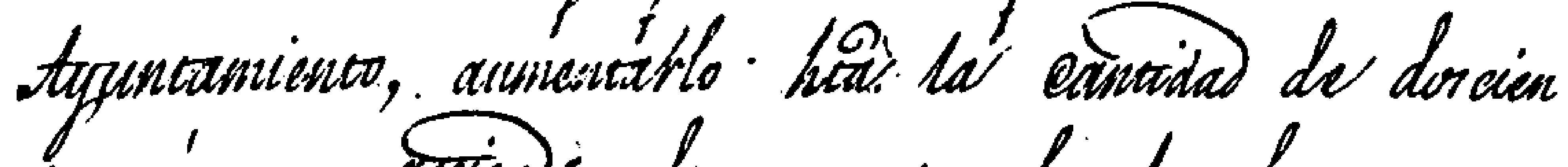
tos a' que exreinde el gasto des ohos faroles, conuma

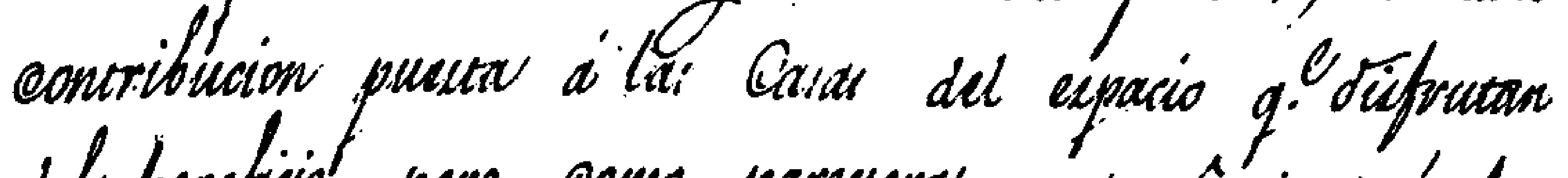

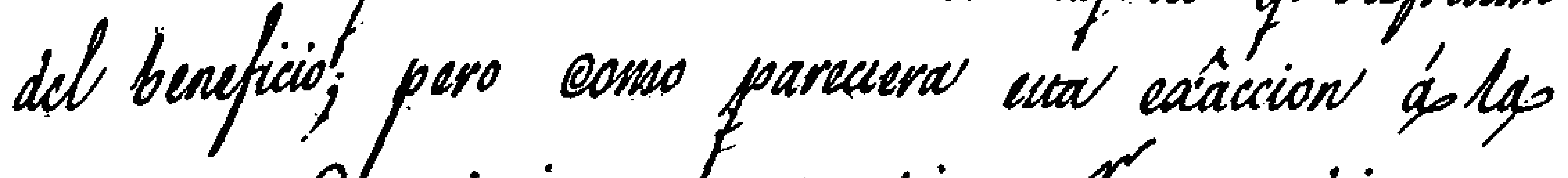

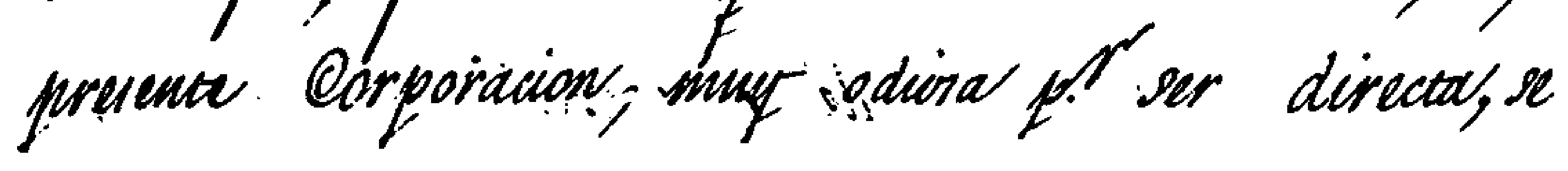


Aunque la suma que resulta no cubre la cantidad que reporta en los cuarenta faroles, como cl cálculo de introducción ha sido más bajo que subido, se espera que mediante una bucna administración, $y$ redoblando la vigilancia produzca hasta llenar los gastos, y si sobrare algún tanto se deberá emplear en carros que exporten la basura para conseguir por este medio la limpieza que es de desear para una bucna policia. Sala de comisiones, 28 de mayo de 1825. Antonio Gómez, Luis Ximénez, Rafael Medina.

Y en cumplimiento del acucrdo de 21 del corriente, doy el presente en la Secretaría del llustre Ayuntamiento de esta ciudad de Aguascalientes a 23 de junio de $1825.9^{\circ}, 4^{\circ}$ y $3^{\circ}$.

Ramón Gómez

Secrelario

El Ayuntamiento de Aguascalientes con fecha 23, del próximo pasado me dice lo que siguc.

Excclentísimo scñor:

El Ayuntamiento precedente planteó el proyecto de alumbrado construyendo 40 faroles de vidrio de donativos que varios particulares hicieron para $\mathrm{cl}$ efecto, mas como para sostención perenne del indicado, y sercnos que los aguarden, fucse indispensable proyectar arbitrios, tocaron en cl de tomar 30 pesos que mensualmente da cl comercio para pagar tres guardas que con el nombre de serenos custodiaban las tiendas por la noche, el producto del degücllo de las reses que se matan, incluidos los cerdos y un real de cada carga de harina, cuyo cobro que asciende a 60 pesos se encontró en práctica. Este causal de 90 pesos prctendió cl precitado anterior Ayuntamicnto, aumentarlo hasta la cantidad de 200 a que ascicnde cl gasto de otros faroles, con una contribución puesta a las casas del espacio que disfrutan del beneficio; pcro como pareciera csta exacción a la presente corporación, muy odiosa por ser dirceta, se trató de substituir la que se ha dirigido al gobicrno que aunque gravita sobre el consumidor, es inscnsible por su indirección y modo de cobrarla; en tal costo y para desarrollar cuanto desca saber el gobicrno digo: Que cxisten 40 faroles, servidos para dos cabos y ocho screnos, que están mantenicndo por el producido cxpresado de 90 pesos y cl fondo que se formó con el donativo que de pronto hicicron algunos individuos, que estando al concluir el último, y descando cl que no retrograde un establecimiento mandado por Reglamento, por ser a todas luces benćfico, se solicita del gobicrno la aprobación de la pensión de la harina y el mezcal, a reserva de proponer otros artículos y subvenir a todo el gasto, porque se ha llegado a entendcr que el primcro aunque está cobrándose no ticne la aprobación, y por lo mismo no debía diferirse a más ticmpo; se cfectuó la propuesta cn oficio de 30 de mayo, y en contestación previene el gobicrno que se haga de todos los arbitrios que 
trato' de subrituir la que se hat diritido al Scbu.

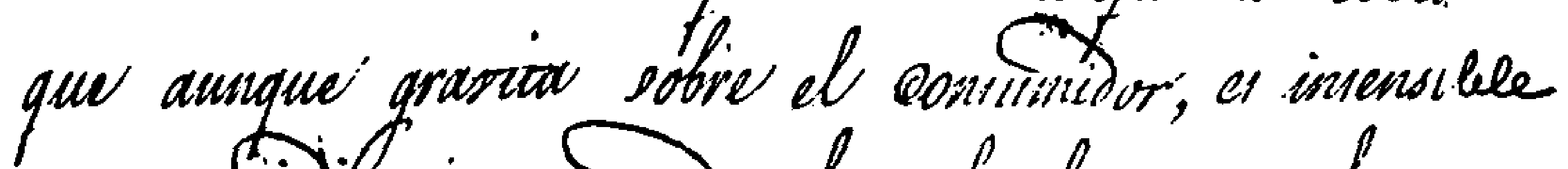
por sutindirecion y modo de orbrarla'; en'taticon to 5 para duarrollar quanto deree suber el Bobn

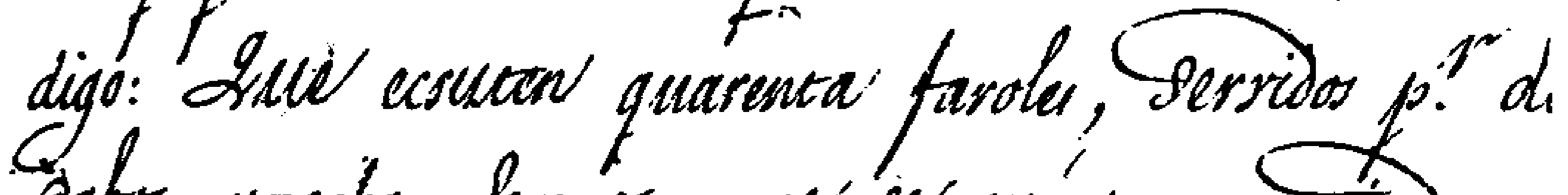

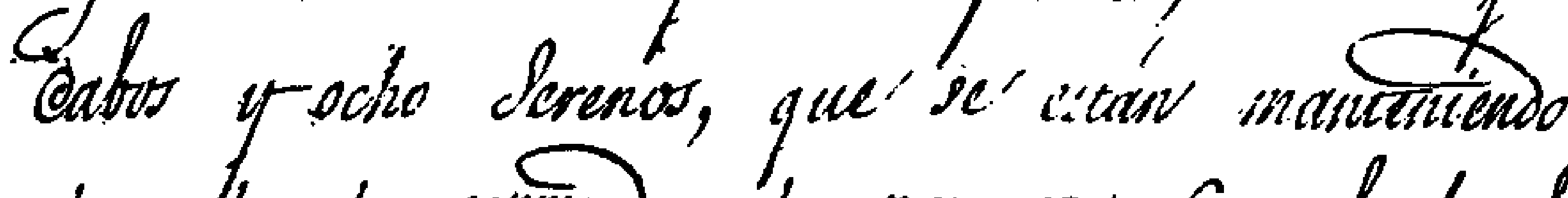
el producado expreado de noventa' per a el fondo $p$ sisformio con' el oronatwo que de pxonto hicieron alla

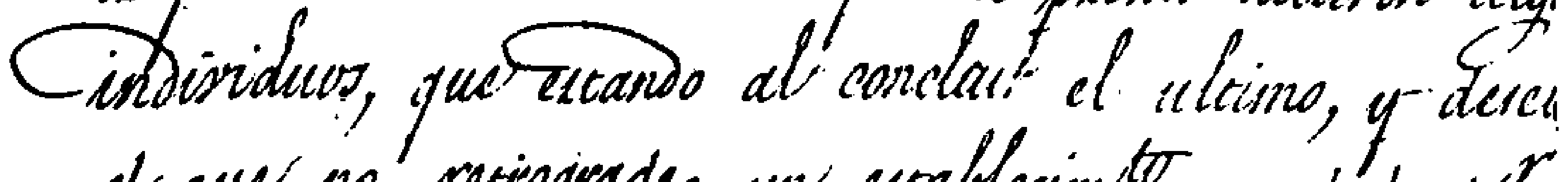
et que no rectrogrades un escablecint to mandado p.r

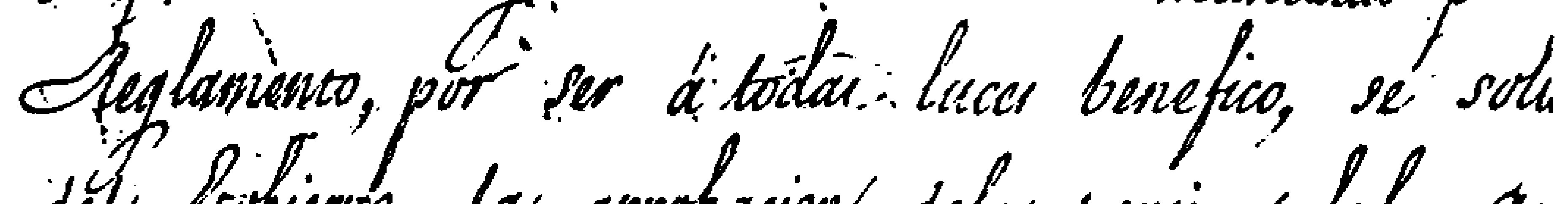
dêt Civbierro la aprobacions dela pernion dela an "yed mexcal, as reversa de proponer otros articulos. subsenir a' tods el gasto, porque se ha llegado.

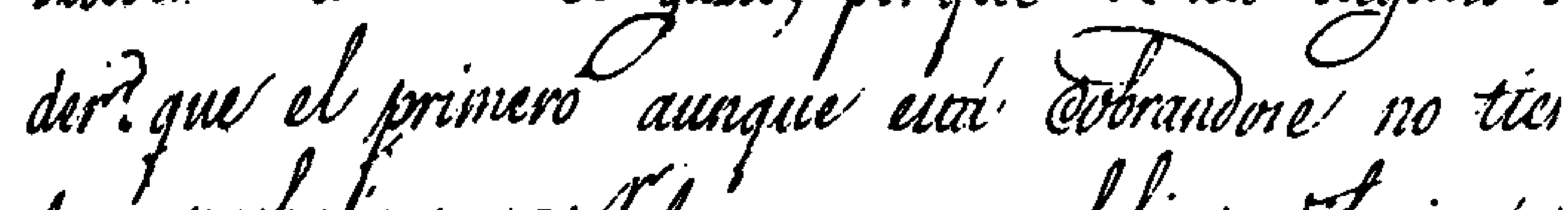

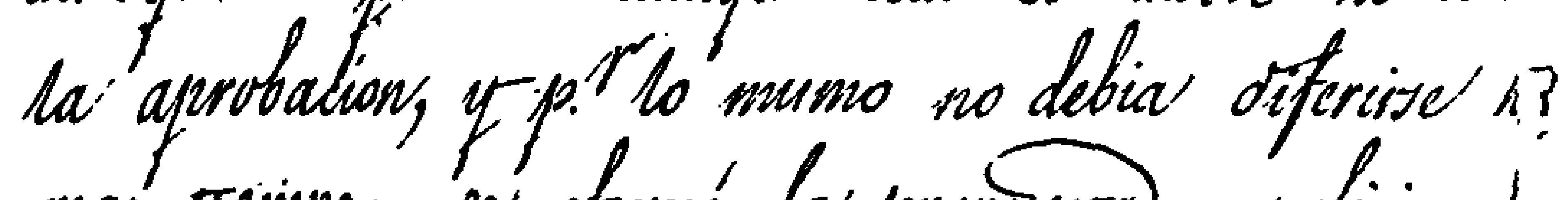

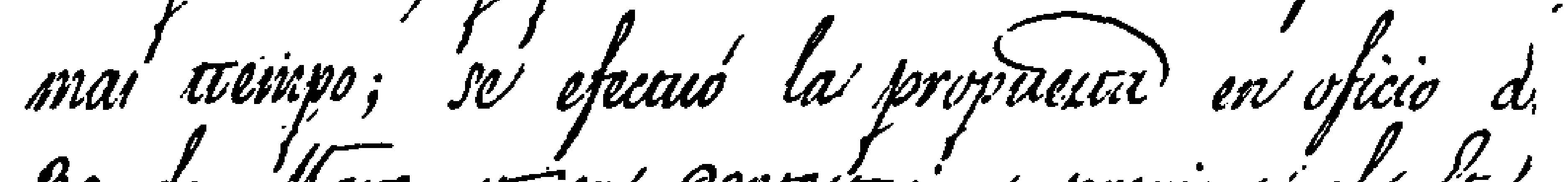

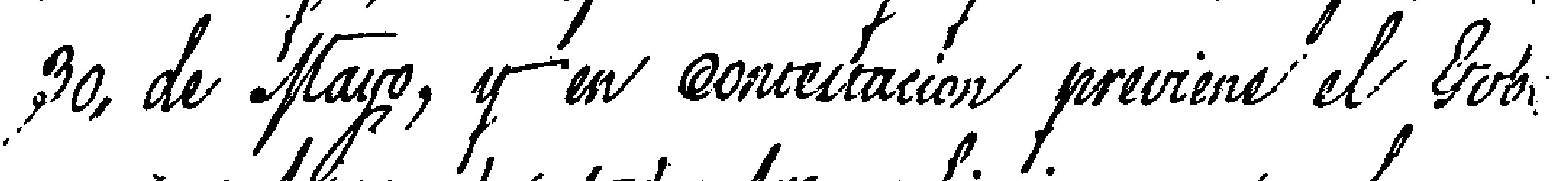
que sehaga de toder lor arbiorios gue sehaurar encogivarsparav Ulenar el aeficis, to yue se orrife alimamino adfuntando las lista delas mercian que debiars gravarse, hor que tampoce cubress' el, tante, pero como sehaya grasuado to imiporth de usau por un calauls prudencial, se prese, 
se hayan escogido para llenar el déficit, lo que se verificó, últimamente adjuntando las listas de las mercadcrías que debían gravarse, los que tampoco cubren el faltante, pcro como se haya graduado la importancia de éstas por un cálculo prudencial, se prevé que apurando la vigilancia resulte todo el haber que se necesita, y con la resolución de que si por casualidad hubiese algún excedente, prodría emplearse en el aumento del alumbrado, y en sus carros para exportar la basura, pues a la verdad en ningún pucblo puede haber policía sin este auxilio. Todo lo expucsto y una copia del proyecto que presentó la comisión nombrada para el caso, idcalizan en mi concepto todo el plan desde el principio de este proyecto, con lo que satisfago el oficio de vuestra excelencia del 17 , del presente.

El plan que comprende todo cste proyecto lo adjunto al $\mathrm{V}$. V. original para que se sirva pasarlo al conocimiento del Honorable Congreso, a cuya alta consideración lo recomiendo, para que siendo de su agrado se sirva aprobarlo, en obsequio de aquella benemérita ciudad.

Casa del estado libre de Zacatecas, julio 5 de 1825. José María García Rojas Manuel Gonzálcz Cosío

Secretaría del Congreso en la Casa del estado libre de Zacatecas, julio 5 de 1825.

Dada cuenta al Congreso con el oficio que precede y documento que le es adjunto, se sirvió mandar en sesión de este dia pase a la comisión de gobicrno. Lo que verificamos en cuatro fojas útilcs.

Campa Juárez

Ciudadanos Diputados Sccretarios del Honorable Congreso Constitucional.

Lectura 8 , octubre 25

Señor:

Impuesta la Comisión de gobierno de la representación que hace el Ayuntamiento de Aguascalientes, solicitando la aprobación del Reglamento, y arbitrios que propone para cl mantenimiento del alumbrado, halla que estando conforme aquél, no tiene nada que cxponer en contrario, no siendo así con los arbitrios, pues éstos deben salir sin costos en aquel vecindario, como quiera que sobre ellos directamente refluye la utilidad, y no sobre los entrantes. En su consecuencia, la comisión propone al Honorable Congreso las siguientes proposiciones que aprobará si las hallare conforme a justicia.

la. Quedan aprobados los tres capítulos que el Ayuntamiento propone para el arreglo del alumbrado. 


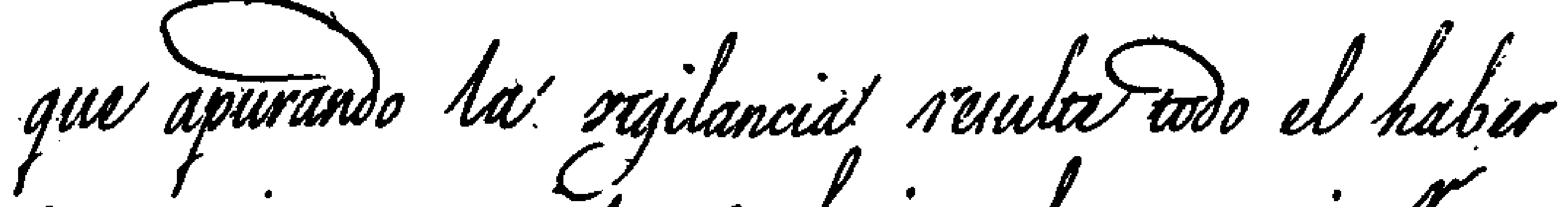
se necuicar, y con la resolucioiv de que si p. "Cares sidad hibive algun excedente, poorion emplearse on

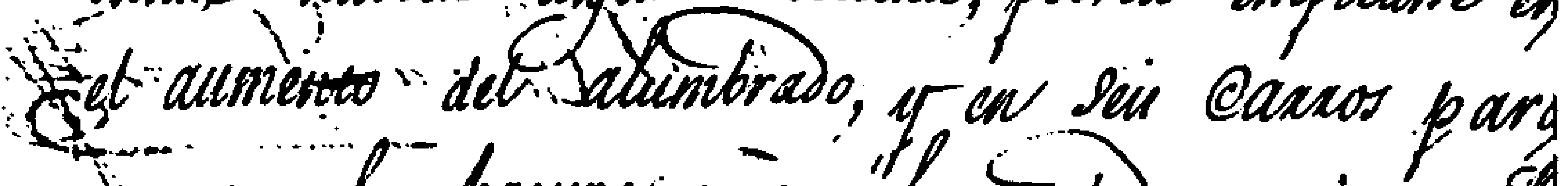

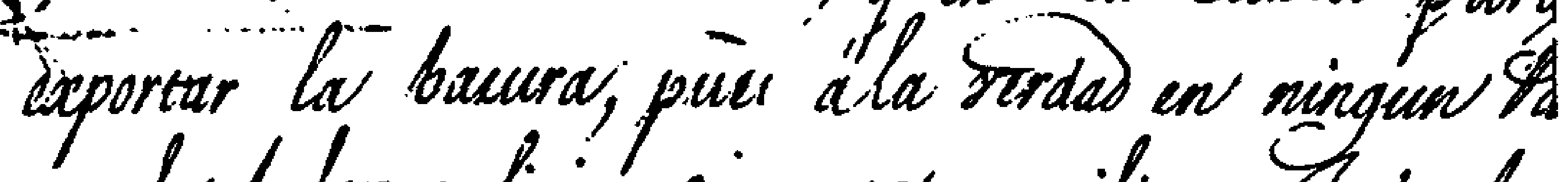
pucte haber policia sin enet auseilio. = Fodo to

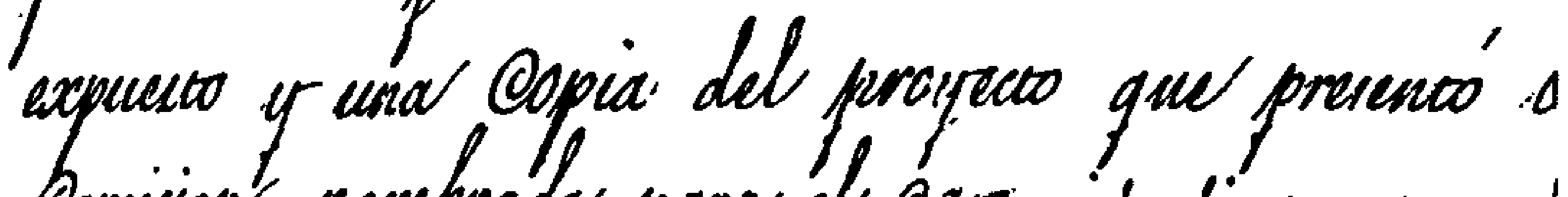
conirions nombrads para el auro, idealizatn en mo concepto todo el plan desdi al princivio de cute. proyecto, con lo que saciafago ialseficio de 2.8 . ds 13) del preunas:

A Elan que compreside : tods ewa proyec to adfunco íl1. originals parai que se sirvan pas to al conocimienco det Moncrable Congres, a alla Conidenacion lo recomisostis para que siendo uw agrado se sirvin aprobarists, an obsequis de' aguellar benemeria Cuidado.

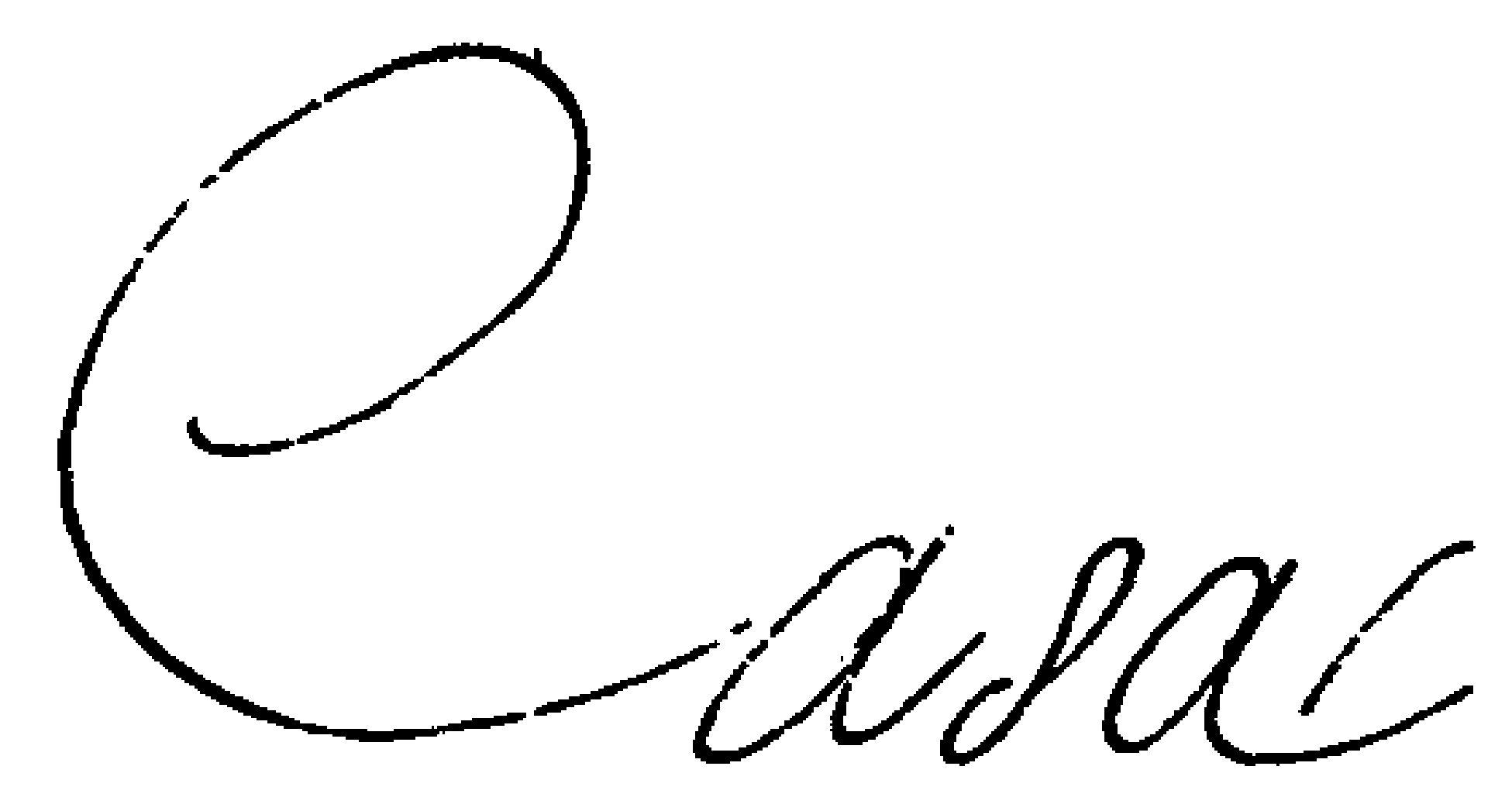


2a. No hay lugar a la aprobación de los arbitrios que propone porque esta pensión parcce más justo la reporte el vecindario que es el que disfruta el beneficio, que no los entrantes, sobre los que gravita inmediatamente.

Sala de Comisioncs, Zacatecas, octubre 27 de 1825

Urizar Calvillo

Excelentísimo scñor:

Habiendo tomado en consideración el Congreso la representación del Ayuntamicnto de Aguascalientes solicitando aprobación de los arbitrios que propone para sostcner el alumbrado de aquella ciudad, ha resuclto:

"Se aprueba el Plan de arbitrios presentado por el Ayuntamiento de Aguascalientes para sostener cl alumbrado de aquella ciudad".

Y lo decimos a vuestra Excelencia de orden del Congreso para su inteligencia y cumplimicnto.

Notaría 5a. novicmbre 8 de 1825

Gutićrrez Sandi Murguía 


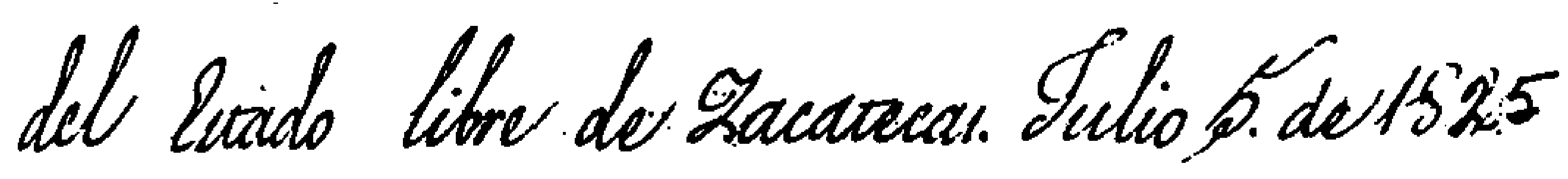

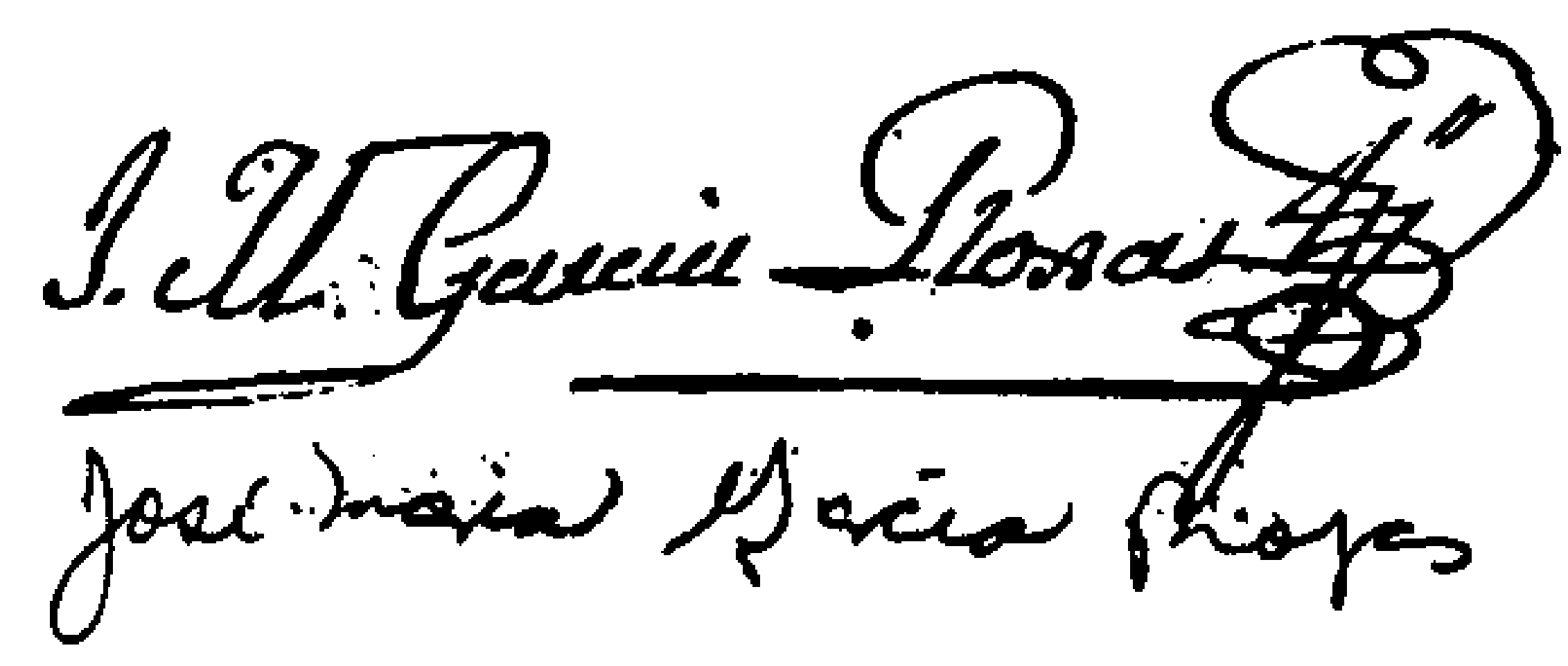

Manuel Gonzagengals

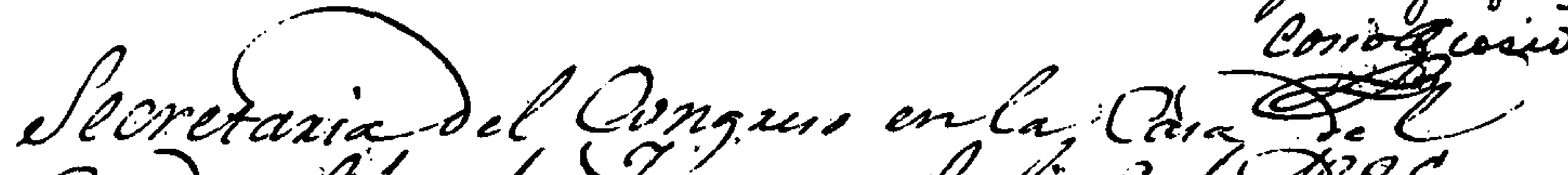

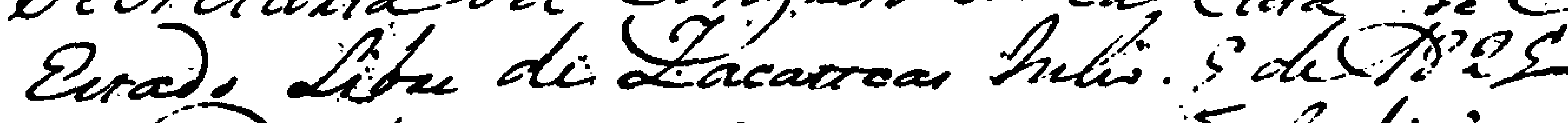

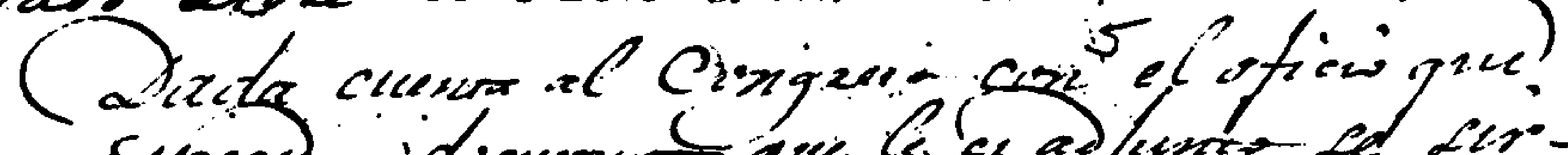

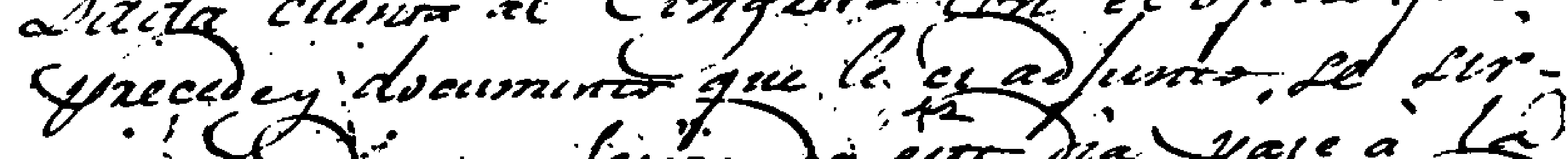

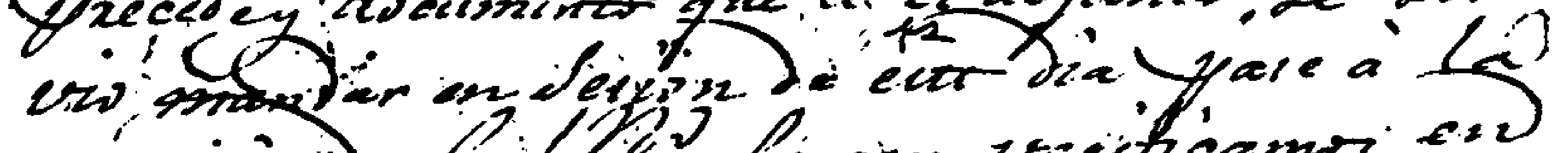

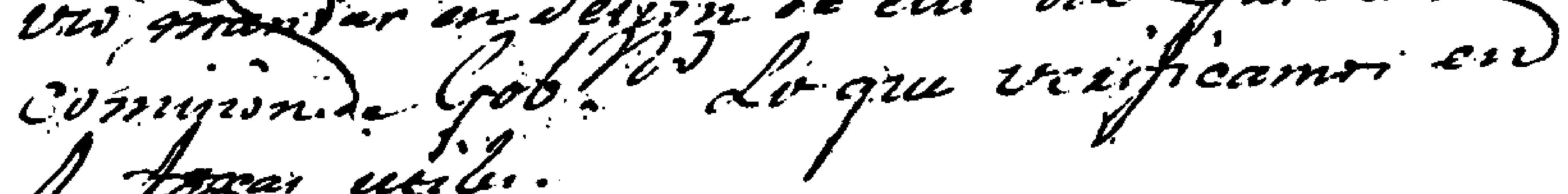
4 forear minites.

(2)
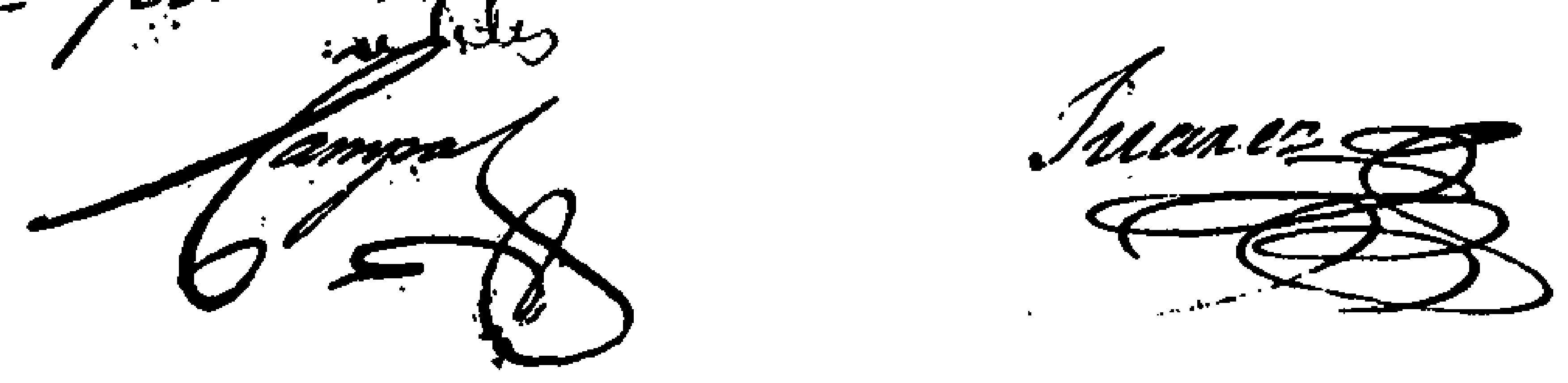

Ouidadanor Odyutador hion del Al. Congreor Comituiconaly' 